\title{
STUDY OF A NEW INHALER (PENHALOR) FOR OBSTETRICAL ANALGESIA*
}

\author{
Shigeru Hatano, M.D., Ph.D. $\nmid$ Max S. Sadove, M.d., Morton Shulman, M.D., \\ Thomas A. Redlin, M.D., Eugenio G. Callegari, M.D., and Hie J. Yoo, M.D.
}

AN INHALER CALLED the $\$$ Analgizer ${ }^{\circledR}$ has been widely used to administer methoxyflurane in analgesic concentrations. When used correctly and appropriately, it has proven to be effective and safe for the control of pain during delivery and minor surgical procedures. Although the Analgizer ${ }^{\circledR}$ provides easy management without complication, this particular technique using methoxyflurane has not achieved clinical popularity, and, from our previous experience as well as from others', at least four reasons appear to have prevented widespread use.

(1) A significant number of the patients experienced difficulties using the device. They found it awkward to inhale through the mouth and exhale through the nose and difficult to remember to do so once the analgesic state was reached.

(2) Clinical analgesia may be poor without energetic guidance and a careful explanation given in advance and continued during administration. This is troublesome.

(3) Since the Analgizer ${ }^{\circledR}$ is designed to be disposable, it is considered by many to be relatively expensive.

(4) Methoxyflurane is still considered an expensive anaesthetic agent and physicians are reluctant to use it in a device through which patients breathe back and forth causing an increase in the consumption of the agent. In addition, condensation of water vapor diminishes efficient vaporization with prolonged use during labor.

For the reasons described above, a new type of inhaler (Penhalor) has been designed. This device works on a principle similar to that of the Cyprane ${ }^{\circledR}$ or Duke ${ }^{\circledR}$ inhalers, both originally designed for the use of trichloroethylene, which have been used all over the world for more than a decade, and which are now being utilized by many with methoxyflurane as the analgesic agent.

\section{The Instrument (Penhalor)}

The Penhalor (Figures 1, 2, and 3) is a cylindrical, lightweight ( $150 \mathrm{~g}$ ) metal tube $15.5 \mathrm{~cm}$. long, with outside diameter $2.5 \mathrm{~cm}$, and inside diameter $2.2 \mathrm{~cm}$. It has a non-rebreathing valve consisting of two thin mica discs at the top of the handle. A side arm located near the top of the handle allows the device to be plugged into a standard anaesthesia mask and to accept the insertion of a disposable plastic mouthpiece. The Penhalor has a small diluter window controlled by a sliding

\footnotetext{
"Division of Anesthesiology, Department of Surgery, Abraham Lincoln School of Medicine, University of Illinois.

†Department of Anesthesiology, University of Illinois Hospitals.

$\$$ Analgizer removed from the market by FDA at present time.
} 


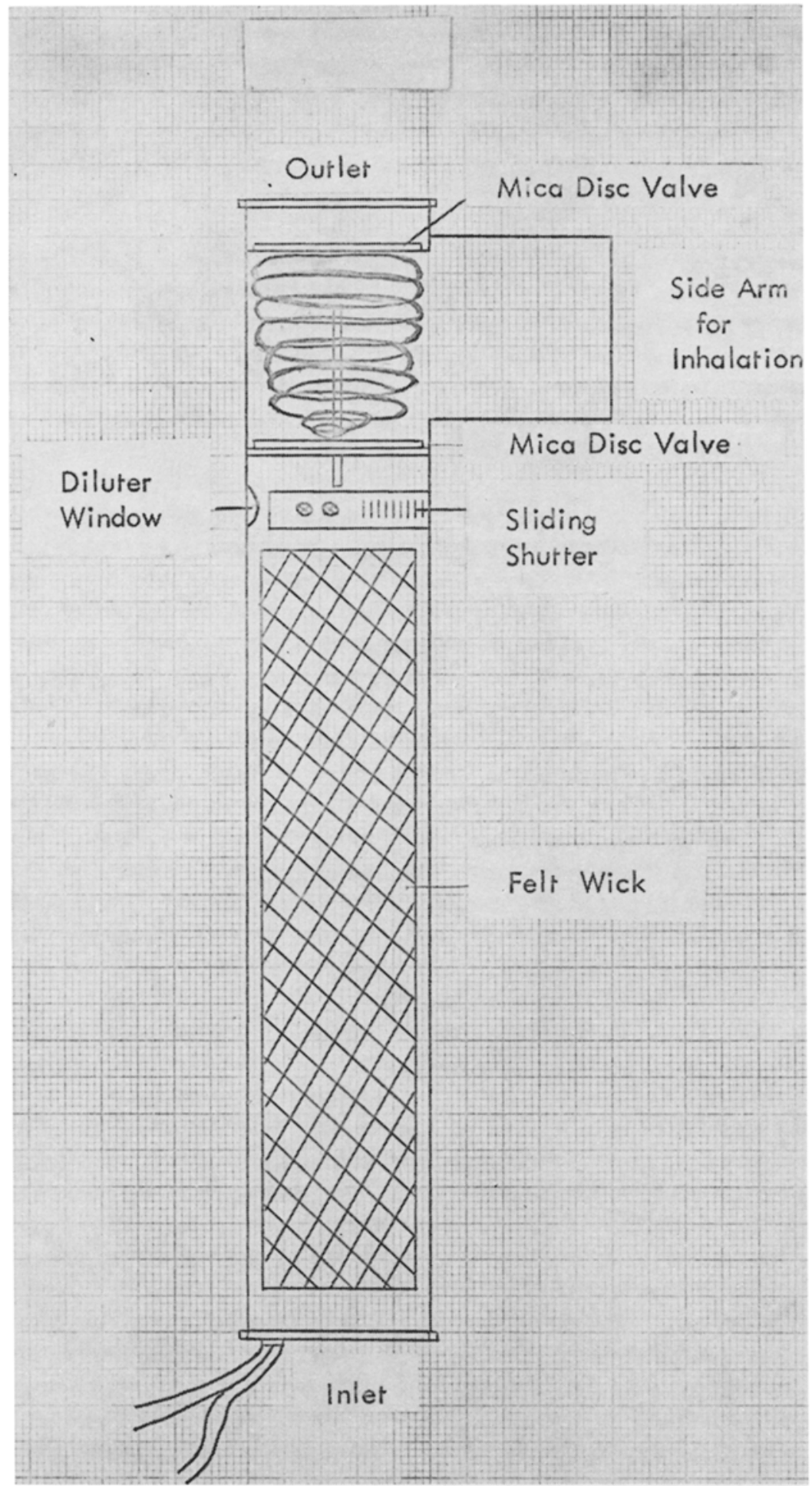

Figure 1 


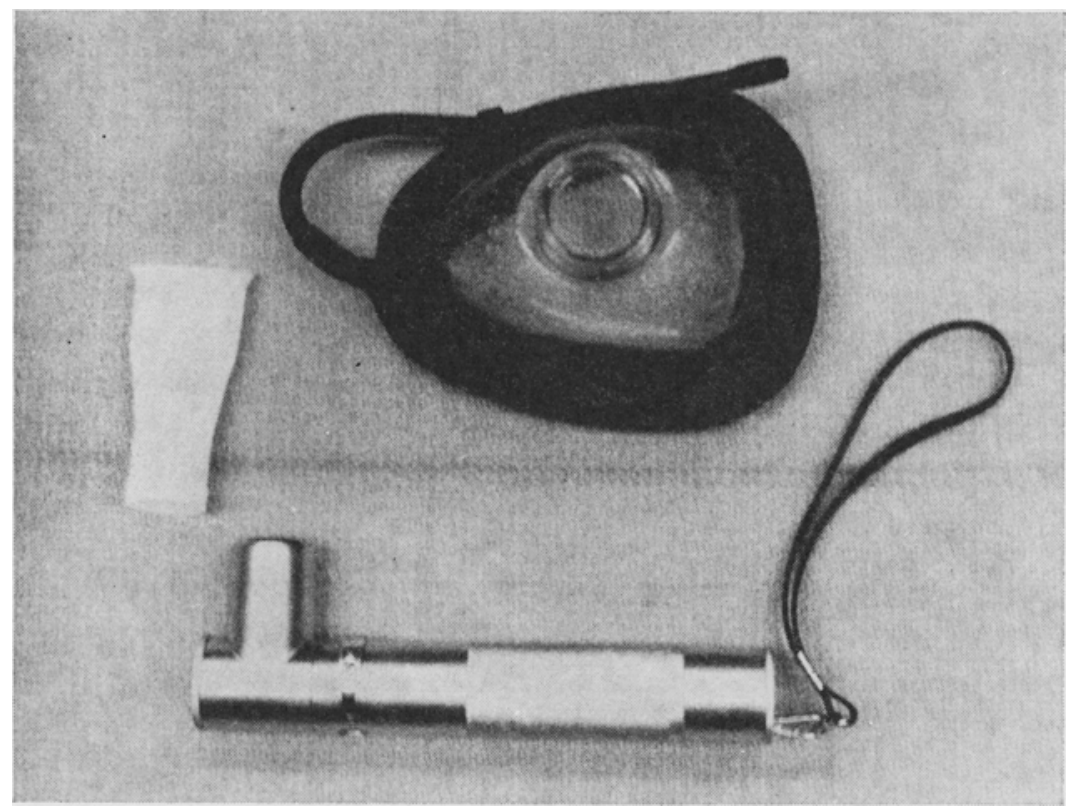

Figure 2

shutter located near the inhalation side valve. When the window remains open, thus activating a partial bypass, the device delivers a diluted analgesic mixture, and as the shutter is closed, higher concentrations of methoxyflurane are obtained. A rolled polyethylene felt wick is placed inside the handle and is saturated with up to $15 \mathrm{cc}$ of methoxyflurane by filling through the inlet orifice. A wrist strap is connected to the bottom of the device to prevent inadvertent dropping and easier retention while in use.

The entire unit can be sterilized easily by autoclave or gas sterilizer, but the wick inside the handle is best removed during sterilization.

\section{Laboratory Studies of the Penhalor}

\section{Laboratory evaluation}

The Penhalor was charged with $15 \mathrm{cc}$ of methoxyflurane and the excess not absorbed by the wick was removed by shaking the device with the valve in the upright position - a standard part of filling procedure. The Penhalor was tested under four different conditions:

(a) Diluter window closed - hand held (the highest concentration)

(b) Diluter window closed - not hand held

(c) Diluter window open - hand held

(d) Diluter window open - not hand held (the lowest concentration).

In each condition, a pseudo-lung was set up so that $500 \mathrm{cc}$ volumes of air were drawn through the Penhalor in such a way as to simulate a standard tidal volume.

The breathing rate of this pseudo-lung was set at eighteen per minute and minute volume was nine liters for all conditions of testing. During each run, a 


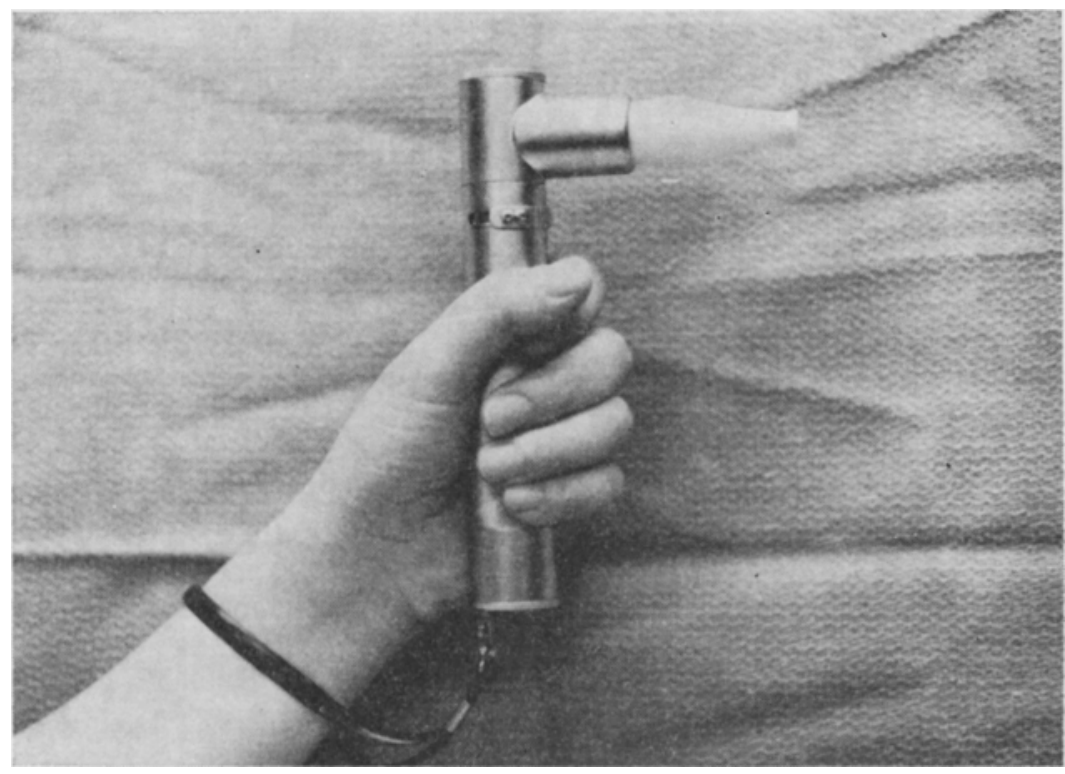

Figure 3

gas sample was withdrawn from the vicinity of the Penhalor mouthpiece every minute and analyzed for methoxyflurane concentration by gas chromatography. The Emerson Assistor-Controller was used to aspirate air through the Penhalor, and a Wright respirometcr was used to measure the tidal volume and minute volumes produced. Research Spccialities Gas Chromatograph and Elektronic Recorder were utilized to study the concentration of methoxyflurane.

\section{Laboratory results}

The results of the laboratory study are shown in Figure 4. Of the four curves under condition (a), the highest concentrations ranged from 0.69 per cent to 0.55 per cent over a 40 -minute period. These concentrations were obtained with the diluter window closed in the hand held technique utilizing continuous ventilator breathing. The concentration then rapidly declined to essentially 0 in 60 minutes. When the diluter window was closed, and not hand held, which is condition (b), the concentration was found to be slightly lower (approximately 0.1 per cent) than with all hand held conditions, but lasted a similar 60 minutes. When the diluter window was opened, concentrations of 0.47 per cent to 0.3 per cent were obtained for 50 minutes, with a drop to essentially 0 at 90 minutes with the hand held condition, and at 80 minutes with the not hand held condition.

From these results, one could expect that the concentrations would be entirely adequate for analgesia. Clinically, where patients ordinarily would be using it only intermittently, the duration of effectiveness should be more than twice that of continuous administration, and one would expect adequate concentration for a period in excess of two hours. During repeated laboratory studies, it was noted that the wick inside the handle swelled and had to be replaced after approximately ten studies. 


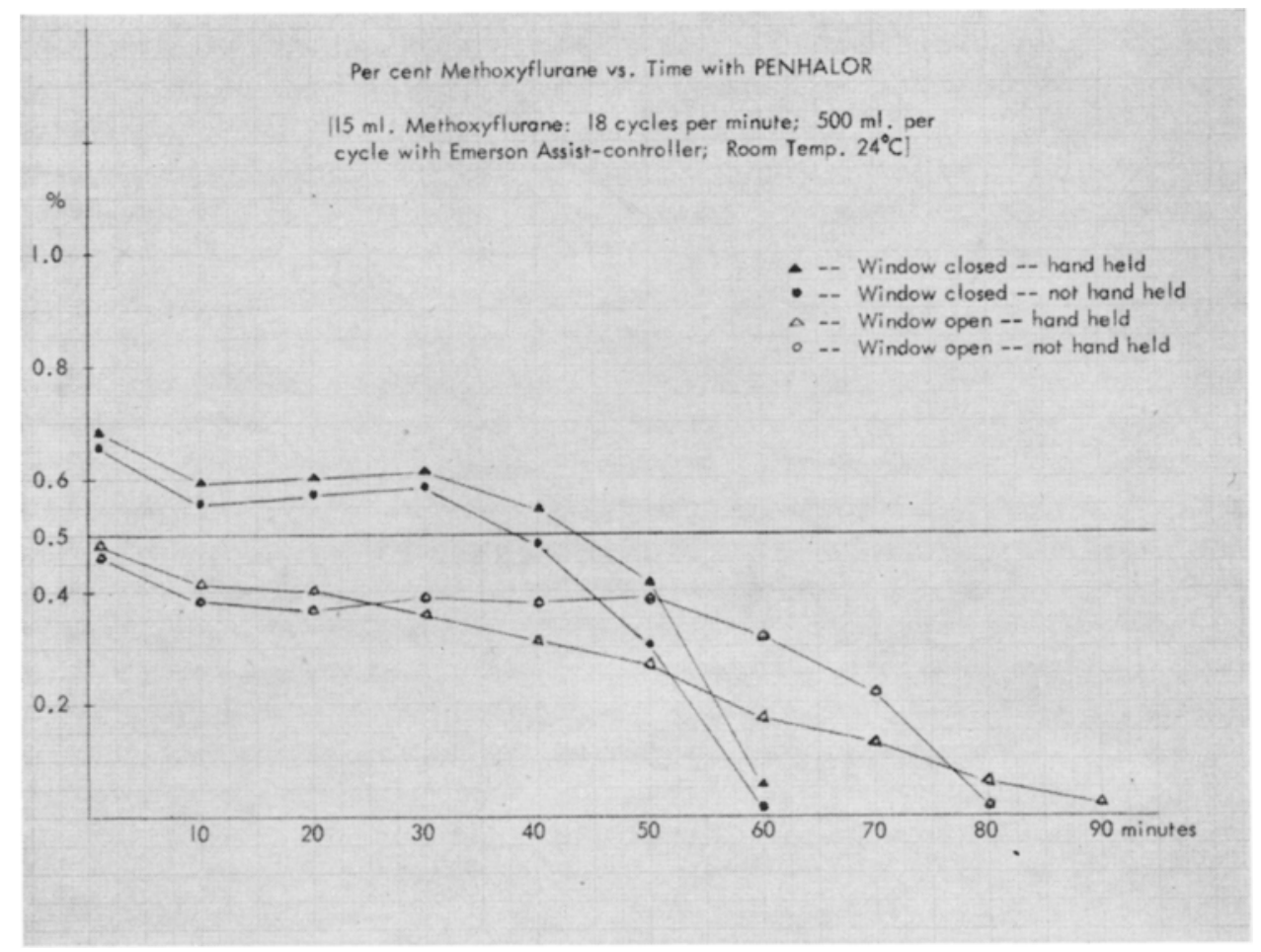

Figure 4

\section{Clinical Study}

\section{Methodology}

Patients. Sixty obstetrical patients (19 primigravida, 41 multigravida) undergoing normal vaginal delivery were selected at random for this study. Their ages ranged from 16 to 43 years (average 25); average body weight was $152 \mathrm{lbs}$; and average weeks of gestation was 39. There was no prior medication given in 52 of the 60 patients.

Method. The patients received instructions about the Penhalor from the physicians, using either the disposable mouthpiece or the mask in the labor room. Selfadministration was instituted when the labor reached the accelerated phase of the first stage. The patient was told to use the Penhalor with the onset of the uterine contraction and to discontinue its use when the contraction ceased. For the first few administrations, while the patients became accustomed to the odor of methoxyflurane, the window of the device was left open to provide a minimal concentration, and then the window was closed for the rest of the period of self-administration.

Observations. For the accuracy of the observations, one of the authors observed the patient throughout the labor. Parameters observed were foetal heart rate, maternal blood pressure, pulse rate and EKG (II), signs such as change of pupillary size, state of consciousness, euphoria, dizziness, sleepiness, headache, salivation, 
nausea, vomiting, and coughing, as well as objective analgesic effect and acceptance of the device. Arterial blood gas studies were carried out in ten patients during labor. As a control, arterial blood samples were drawn from the radial or brachial artery using 25 guage needles before self-administration was begun, and then the $\mathrm{pH}, \mathrm{PO}_{2}, \mathrm{PCO}_{2}$, base excess and standard bicarbonate were determined using the Astrup micro $\mathrm{pH}$ meter every one hour period for four hours or up to delivery. The Apgar scores were observed at one minute and five minutes after delivery.

The day following the delivery, the patients were questioned about their general impression and acceptance of the device, and the effectiveness of pain relief during labor. These findings were recorded in the specially prepared work sheet.

\section{Results}

The results obtained from this study are as follows:

(a) Total time of labor and inhalation: The mean duration of labor was 10 hours and 55 minutes in the primigravida and 7 hours 25 minutes in the multigravida. The average total time of analgesia during labor was 1 hour 50 minutes in the primigravida and 1 hour 23 minutes in the multigravida.

The mean cervical dilatation at the time self-administration was started was $6 \mathrm{~cm}$ in 60 patients; $7 \mathrm{~cm}$ in the primigravida and $5.9 \mathrm{~cm}$ in the multigravida.

TABLE I

Acceptance and EFfect

\begin{tabular}{lllll}
\hline \hline & Poor & Fair & Good & Excellent \\
\cline { 2 - 5 } & & & & \\
Acceptance & $2(3.3 \%)$ & $3(5 \%)$ & $21(35 \%)$ & $34(56.6 \%)$ \\
Objective & $2(3.3)$ & $4(6.7)$ & $21(35)$ & $33(55.0)$ \\
Subjective & $2(35)$ & $14(23.3)$ & $18(30.0)$ & $20(33.3)$ \\
Analgesic & $8(13.3)$ & 14 & & \\
effect & & & & \\
\hline
\end{tabular}

(b) Acceptance of the Penhalor technique (Table I): The degree of acceptance was classified both objectively and subjectively as poor, fair, good, and excellent. A small number of patients showed poor acceptance of the technique primarily because of the odor of the agent or difficulties in handling the device. In approximately 90 per cent of the patients, evaluation was good and/or excellent both objectively and subjectively.

(c) Analgesic effect (Table I): Effectiveness was classified as excellent, good, fair, and poor. The total number of good and excellent impressions was 38 (63 per cent); fair was 14 ( 23 per cent); and poor was 8 ( 13 per cent). Of the patients who classified it as poor, two patients disliked the odor of the agent. Four utilized it only a few minutes because their labor progressed so quickly that there was little time to establish an effective concentration.

(d) Maternal side effects (Table II): Dizziness was noted in 41 (72 per cent) of 60 patients. It was marked in 2 ( 3.3 per cent), moderate in 9 ( 15 per cent), and mild in 32 ( 53 per cent) patients. Sleepiness was noted in 9 ( 15 per cent) patients: marked in 2 ( 3.3 per cent), moderate in 1 ( 1.6 per cent), and mild in 6 (10 per 
TABLE II

SIDE EFFECTS

\begin{tabular}{|c|c|c|c|c|}
\hline & $\begin{array}{l}0 \text { or } \\
\text { None }\end{array}$ & $\begin{array}{l}+ \text { or } \\
\text { Mild }\end{array}$ & $\begin{array}{c}++ \text { or } \\
\text { Moderate }\end{array}$ & $\begin{array}{l}+++ \text { or } \\
\text { Marked }\end{array}$ \\
\hline Nausea & $\begin{array}{c}53 \\
(88.3 \%)\end{array}$ & $(11 . \stackrel{7}{7} \%)$ & $\begin{array}{c}0 \\
(-\%)\end{array}$ & $\begin{array}{c}0 \\
(-\%)\end{array}$ \\
\hline Vomiting & $\begin{array}{c}53 \\
(88.3)\end{array}$ & $\begin{array}{c}5 \\
(8.3)\end{array}$ & $\begin{array}{c}2 \\
(3.3)\end{array}$ & 0 \\
\hline Salivation & $\begin{array}{c}52 \\
(86.7)\end{array}$ & $\begin{array}{c}8 \\
(13.3)\end{array}$ & 0 & 0 \\
\hline Coughing & $\begin{array}{c}\mathbf{5 8} \\
(96.7)\end{array}$ & $\begin{array}{c}2 \\
(3.3)\end{array}$ & 0 & 0 \\
\hline Pupil Change & $\begin{array}{c}60 \\
(100)\end{array}$ & 0 & 0 & 0 \\
\hline Euphoria & $\begin{array}{c}57 \\
(95.0)\end{array}$ & $\left(\begin{array}{c}3 \\
(5.0)\end{array}\right.$ & 0 & 0 \\
\hline Dizziness & $\begin{array}{c}17 \\
(28.3)\end{array}$ & $\begin{array}{c}32 \\
(53.3)\end{array}$ & $\begin{array}{c}9 \\
(15.0)\end{array}$ & $\begin{array}{c}2 \\
(3.3)\end{array}$ \\
\hline Sleepiness & $\begin{array}{c}51 \\
(85.0)\end{array}$ & $\begin{array}{c}6 \\
(10.0)\end{array}$ & $\begin{array}{c}1 \\
(1.7)\end{array}$ & $\begin{array}{c}2 \\
(3.3)\end{array}$ \\
\hline Headache & $\begin{array}{c}60 \\
(100)\end{array}$ & 0 & 0 & 0 \\
\hline
\end{tabular}

cent) of the patients. Mild euphoria was observed in only 3 patients ( 5 per cent). Nausea was noted in 7 patients ( 12 per cent); 5 patients ( 8.3 per cent) had mild vomiting. There was a mild increase in salivation observed in 8 (13 per cent) patients. There were no headaches reported. No marked changes in blood pressure, pulse rate, or EKG were observed.

(e) Apgar score (Table III): Apgar scores were observed at one and five minutes after birth. In 52 of 60 newborns ( 93 per cent), the Apgar score at one minute was 6 or greater. Only in 4 newborns was the Apgar score below 4. In 49 newborns (82 per cent) an Apgar score of 9 or 10 was found after one minute; 57 (95 per cent) had an Apgar score of 9 or 10 after five minutes. Three of the low Apgar score newborns had established compression of the cord around the neck, and in one case aspiration of amniotic fluid was noted by the obstetrician. After five minutes, only one newborn was still below 4 in Apgar score and this baby recovered uneventfully thereafter. None of these low scores were recognized as being related to the analgesic technique.

(f) Arterial blood gas study (Table IV): Blood gas studies were carried out in 10 patients. All patients coming into labor had moderate respiratory alkalosis and

TABLE III

APGAR SCORE

\begin{tabular}{|c|c|c|c|c|c|c|c|c|c|c|}
\hline & 1 & 2 & 3 & 4 & 5 & 6 & 7 & 8 & 9 & 10 \\
\hline $\begin{array}{l}1 \text { Minute } \\
\text { per cent }\end{array}$ & $\stackrel{1}{(1.7)}$ & $\begin{array}{c}1 \\
(1.7)\end{array}$ & $\begin{array}{c}0 \\
(0)\end{array}$ & $\begin{array}{c}2 \\
(3.3)\end{array}$ & $\begin{array}{c}0 \\
(0)\end{array}$ & $\begin{array}{c}1 \\
(1.7)\end{array}$ & $\begin{array}{c}2 \\
(3.3)\end{array}$ & $\begin{array}{c}4 \\
(6.6)\end{array}$ & $\begin{array}{c}23 \\
(38.3)\end{array}$ & $\begin{array}{c}26 \\
(43.3)\end{array}$ \\
\hline $\begin{array}{l}5 \text { Minutes } \\
\text { per cent }\end{array}$ & $\begin{array}{c}0 \\
(0)\end{array}$ & $\begin{array}{c}0 \\
(0)\end{array}$ & $\stackrel{1}{(1.7)}$ & $\begin{array}{c}0 \\
(0)\end{array}$ & $\begin{array}{c}0 \\
(0)\end{array}$ & $\begin{array}{c}0 \\
(0)\end{array}$ & $\begin{array}{c}0 \\
(0)\end{array}$ & $\begin{array}{c}2 \\
(3.3)\end{array}$ & $\begin{array}{l}3 \\
(4.9)\end{array}$ & $\begin{array}{c}54 \\
(90.0)\end{array}$ \\
\hline
\end{tabular}


TABLE IV

BLOOD Gas Analysis

\begin{tabular}{lccccc}
\hline & Before & 60 & 120 & 180 & 240 \\
\cline { 2 - 6 } & 7.49 & 7.48 & 7.47 & 7.40 & 7.51 \\
$\mathrm{PH}$ & 112.3 & 106.1 & 104 & 96.67 & $\mathbf{1 1 7 . 5}$ \\
$\mathrm{PO}_{2}(\mathrm{mmHg})$ & 24.9 & 21.9 & 24.4 & $\mathbf{1 9 . 5}$ \\
$\mathrm{PCO}_{2}(\mathrm{mmHg})$ & 23.9 & 24.9 &
\end{tabular}

the mean $\mathrm{pH}$ was 7.49, $\mathrm{Po}_{2}$, was 112.3 , and $\mathrm{PCO}_{2}$ was 23.9. As shown in Table IV, there was a slight improvement in $\mathrm{pH}$ observed, but no remarkable change was noted in $\mathrm{Po}_{2}, \mathrm{PCO}_{2}$, base excess, and standard bicarbonate.

(g) Supplemental analgesia: Shortly before delivery, 39 patients (65 per cent) received pudendal blocks, 8 patients ( 13 per cent) received saddle blocks, 3 ( 5 per cent) received local infiltration, and 10 patients ( 17 per cent) received no supplemental analgesia.

\section{Discussion and Summary}

Because obstetrical analgesia is an integral portion of the anaesthesiologists' area of interest, the authors attempted to design a unit that would be ideal for the average obstetrical patient. There was a desire to have the unit fit the hand of the average female easily, be lightweight, rugged, predictable, free from administration problems, and to have the ability to be connected either to a mask or mouthpiece. In addition, it had to be easily sterilizable and less costly in use than the Analgizer. After several modifications of the Analgizer ${ }^{\circledR}$ were made by one of the authors (S.H.), the Penhalor was finally attained.

Laboratory data indicated that the concentration of methoxyflurane at the extremes of conditions that might be expected in the labor or delivery room, would range from a low of 0.3 per cent to a high of 0.7 per cent. However, in the area of clinical usage, it was likely that the concentration would be approximately 0.5 per cent. a concentration ordinarily considered ideal for the conditions of clinical analgesia.

Although one might have predicted nearly all of the results simply by knowing the concentration from the laboratory, it was thought necessary to determine the values on a clinical basis: therefore, a relatively small number of patients was utilized to add to the laboratory data. It was felt that the number of cases was adequate to determine that the instrument met the basic criteria of acceptance and provided adequate analgesia. There were no significant side effects seen in the study except for the subjective complaint of dizziness noted in approximately 70 per cent of the patients. Apgar scores in the newborn were no lower than one might anticipate with deliveries in unmedicated mothers or in other delivery "schemes." In fact, the technique in no way added significantly to the lowering of the Apgar score - although it is to be expected that in the distressed infant or in extremely prolonged exposure to the agent, a slight depressant effect on the central nervous system of the newborn distressed child would be found. The results obtained from the blood gas studies were essentially similar to those reported by others using the Analgizer ${ }^{\mathbb{B}}$ and were all within normal limits. 
Heavily premedicated patients were not utilized in this study, yet it is quite possible that patients using methoxyflurane analgesia might, under certain circumstances, be heavily premedicated. Under such conditions, the lower concentration technique would be advisable. Nevertheless, any patient who is having an agent as potent as methoxyflurane must be observed continuously.

It is anticipated that over the next few years, this instrument will be increasingly utilized in routine obstetrical analgesia as well as analgesia in the operating room and in other areas where desired. Under these conditions, further data will be gathered regarding the ruggedness and durability of the instrument; however at this time the authors are satisfied that clinical conditions simulate the data obtained from their studies. The authors believe that the instrument is worthy of investigation and utilization by trained and partially trained individuals as well as by patients during self-administration with adequate supervision.

In summary, the advantages and disadvantages of the Penhalor are as follows. Advantages:

(a) The non-rebreathing valve prevents bidirectional flow of air over the Penhalor wick thus conserving methoxyflurane and eliminating the need to train the patient to inhale through his mouth and exhale through his nose.

(b) Elimination of rebreathing over the vaporization chamber prevents water condensation in the wick and waste of the agent. It also provides for a more constant concentration from the Penhalor.

(c) Because of the sliding shutter, the patient is not required to keep a finger over the orifice in order to deliver an increased concentration of the agent.

(d) Relative safety in maximum concentration exists because of the wide margin of safety of the methoxyflurane.

(e) The metal body conducts heat from the patient's hand and enhances the vaporization of methoxyflurane.

(f) The ninety degree angle of the mouthpiece allows one to hold and use the instrument easily.

(g) The device disassembles and reassembles easily for cleaning and replacement of parts.

(h) Oxygen can be given through the inlet.

(i) The Penhalor can be readily sterilized.

(j) Reusability provides for economy.

Disadvantages:

(1) Instrument:

(a) Does not allow for assisted or controlled respiration.

(b) Does not have exact and wide range of concentrations which might be necessary in some cases.

(c) The felt wick inside the handle should be removed during sterilization.

(d) The wick should be replaced after use by approximately ten patients because of gradual swelling which might increase respiratory resistance.

(2) Methoxyflurane analgesia:

(a) Patient may have methoxyflurane accumulation after prolonged administration.

(b) Special consideration is required for the patient who has eclamptic, hepatic, and especially renal problems. 
(c) Patient history of hypersensitivity to the methoxyflurane should be studied.

(d) Interaction of methoxyflurane and tetracycline should be considered.

(e) Careful and continuous observation of patient is necessary.

(f) Resuscitation equipment should be always available.

(g) Reaction to agent odor by others in the room should be considered.

\section{Conclusion}

The authors have presented a new type of methoxyflurane analgesic inhaler (Penhalor) which will be advantageous from the standpoint of safety, effectiveness, simplicity, maintenance, utilization, and economy in the administration of obstetrical and clinical analgesia.

\section{RÉSUME}

Les auteurs présentent un nouveau genre d'inhalateur analgésique de méthoxyflurane; cet appareil est avantageux du point de vue sécurité, efficacité, simplicité, entretien, utilisation et économie pour l'administration de l'analgésie obstétricale et clinique.

Parce que l'analgésie obstétricale fait partie intégrante du domaine de l'anesthésiologiste, les auteurs ont imaginé, pour l'analgésie au méthoxyflurane, un appareil qui s'adapte facilement à la main d'une femme, qui est léger, rugueux, exempt de problèmes d'administration ct qui peut s'adapter à un masque ou à un circuit.

Les données ct les conclusions tant au laboratoire que pour 60 cas cliniques ont montré que cet appareil donne la concentration idéale pour l'analgésie clinique. Il n'y a pas eu d'effets nocifs à mentionner chez la mère ou selon les données d'Apgar. Les auteurs croient que cet instrument mérite d'être étudié et utilisé par des anesthésistes certifiés ou en période de formation aussi bien que par les malades durant l'auto-administration à condition qu'ils soient bien surveillés.

\section{ACKNOWLEDGEMENT}

The authors are deeply grateful to Dr. Ralph M. Wynn, Professor and Head of the Department of Gynecology and Obstetrics at the University of Illinois Hospital; and Dr. Arthur Shima, the Head of the Department of Anesthesiology at West Suburban Hospital in Chicago; Dr. Jose F. Gonzalez, Assistant Medical Director of the International Division of Abbott Laboratories in North Chicago; and to Dr. Richard Thomason, Mr. Larry Brown, Mr. Eugene Jobgen, Mrs. Deane Lieberman, and Mrs. Eloise Williams for their cooperation and assistance.

\section{REFERENCES}

FujII, A. Penthrane anesthesia with the Analgizer. J. Obst. Anesth., 29: 23 (1970).

Hattoni, S. Penthrane anesthesia with the Analgizer. J. Obst. Anesth., 29: 8 (1970).

Hicks, J. T. Analgizer and Penthrane, Hosp. Formulary Management, 3: 22 (1968).

Hols, J. W. \& Shnider, S. M. Methoxyflurane concentrations from the Cyprane inhaler. Anesthesiology, 28: 770 (1967).

Koyama, T. Penthrane anesthesia using the Analgizer. J. Obst. Anesth., 29: 1 ( 1970). 
LAMBie, R. S. The analgesia of methoxyflurane. Canad. Anaesth. Soc. J., 10: 469 (1963).

Major, V.; Rosen, M.; \& Mushin, W. W. Methoxyflurane as an obstetric analgesic: a comparison with trichloroethylene. Brit. Med. J., 2: 1554 (1966).

Major, V.; Rosen, M.; \& Mushin, W. W. The concentration of methoxyflurane for obstetric analgesia by self-administered intermittent inhalation. Brit. Med. J., 4: 767 (1967).

Marx, G. I.; Chen, L. K.; \& Tabora, J. A. Experiences with a disposable inhaler for methoxyflurane analgesia during labor: clinical and biochemical results. Canad. Anaesth. Soc. J., 16: 66 (1969).

Nozare, G. \& Ito, H. Methoxyflurane-anesthetized deliveries by use of the Analgizer. J. Obst. Anesth., 29: 20 (1970).

Samdman, L. J.; Eger, E. L.; Munson, E. F.; Babad, A. A.; \& Muallem, M. Minimal alveolar concentrations of Methoxyflurane, halothane, ether and cyclopropane in man: Correlation and theories of anesthesia. Anesthesiology, 28: 994 (1967).

Takahashi, T, Alleviated deliveries with Penthrane Analgizer. J. Obst. Anesth., 29: 12 (1970).

Reports of the Medical Department, Hospital Products Division, Abbott Laboratories, 19671968.

Report of the Medical Director, Europe and Pacific Areas, Abbott Laboratories Universal, 19681969.

Report of the Medical Director, Latin American Area, Abbott Laboratories Universal, 1968 and 1969.

Abbott Laboratories: Information for clinical investigators, 1970. 